Risk Sharing and the Demand for Insurance: Theory and Experimental Evidence from Ethiopia

Erlend Berg Michael Blake Karlijn Morsink

Discussion Paper 21/742

October 2020

School of Economics

University of Bristol Priory Road Complex Bristol BS8 1TU United Kingdom

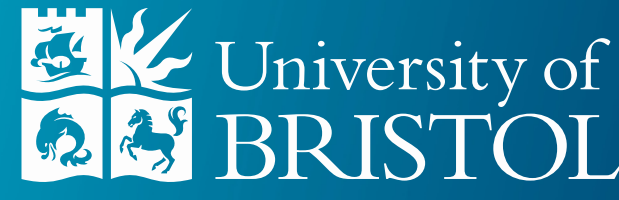

School of Economics 


\title{
Risk Sharing and the Demand for Insurance: Theory and Experimental Evidence from Ethiopia
}

\author{
Erlend Berg, Michael Blake and Karlijn Morsink*
}

October 2020

\begin{abstract}
Households in developing countries commonly engage in risk sharing to cope with shocks. Despite this, the residual risk they remain exposed to - often due to aggregate events such as droughts and floods - is considerable. To mitigate these risks, governments, NGOs and multilateral organizations have introduced index insurance. To appreciate its welfare implications, however, we need to assess how insurance interacts with pre-existing risk sharing. We ask to what extent the demand for index insurance - as compared to standard indemnity insurance depends on the level of pre-existing risk sharing. We contribute by developing a simple theoretical framework which shows that, relative to a state of autarky, risk sharing between agents increases demand for index insurance and decreases demand for indemnity insurance. In an artefactual field experiment with Ethiopian farmers who share risk in real life, we test and confirm these predictions.
\end{abstract}

JEL: D14, D81, G22, O16

Key words: risk sharing, indemnity insurance, index insurance, artefactual field experiment

\section{INTRODUCTION}

Households in developing countries commonly share risk with family, friends and community members through transfers and emergency loans (Fafchamps and Lund, 2003). Despite this, they remain exposed to considerable residual risk (Townsend, 1994). In particular, aggregate shocks such as droughts and floods reduce the ability of simultaneously affected individuals to insure each other (Samphantharak and Townsend, 2018). In recent years there has been a surge in initiatives introducing insurance to mitigate these

${ }^{*}$ Berg (corresponding author): University of Bristol, School of Economics, Priory Road Complex, Bristol BS8 1TU, United Kingdom, erlend.berg@bristol.ac.uk. Blake: Pricoa Private Capital. Morsink: Utrecht University.

We are indebted to Tagel Gebrehiwot Gidey for research coordination. We are grateful for useful comments from Daniel Clarke, Stefan Dercon, Glenn Harrison, Mahreen Mahmud, Costas Meghir, Kalle Moene, Ollie Ramsey, Debraj Ray, Jim Roth, Elisabeth Sadoulet and audiences at the University of Bristol, the University of Kent, the 2017 CSAE conference, 2017 SEEDEC conference, and 2017 DIAL conference. This paper is an output of Improving Institutions for Pro-Poor Growth (iiG), a research programme funded by the UK Department for International Development. Views expressed are not necessarily those of the funder. Declarations of interest: none. 
risks. This is especially so in Asia and Africa, where large investments have been made by countries, donor agencies and multilateral organizations (Clarke and Dercon, 2016).

Standard indemnity insurance, which covers individual-specific losses, tends to be costly and fraught with asymmetric-information problems in this context. It has, therefore, increasingly been supplemented by index insurance. Index insurance provides payouts based on objectively verifiable indices, such as measures of rainfall or average yield, which are positively but imperfectly correlated with actual losses. ${ }^{1}$ Index insurance has the potential to reduce moral hazard and adverse selection as well as claim verification costs. However, to assess the welfare implications of insurance it is important to consider how it interacts with pre-existing informal risk sharing. It is already known that introducing indemnity insurance may not enhance welfare if the pre-existing risk-sharing arrangement and the formal insurance contract provide protection against the same risk (Arnott and Stiglitz, 1991; Attanasio and Ríos-Rull, 2000; Attanasio and Ríos-Rull, 2000). However, the interaction between index insurance and pre-existing risk sharing is potentially different and requires investigation.

In this paper we study how demand for index insurance, as well as indemnity insurance, depends on the extent of pre-existing risk sharing. The paper makes two main contributions. The theoretical contribution is to model how demand for both types of insurance depends on risk sharing in a single, simple, framework which combines aggregate and idiosyncratic risk. We show that risk sharing increases demand for index insurance, while confirming the familiar result that it decreases demand for indemnity insurance. Intuitively, this is because the greater the extent of risk sharing, the more the residual risk of the agents relates to group-level rather than idiosyncratic shocks. Risk sharing is therefore a substitute for indemnity insurance, while it acts as a complement to index insurance by pooling individual-specific shocks, including the possibility that index insurance does not pay out when an individual suffers a loss. Relative to the existing literature in this area, the simplicity of our model enables us to derive closed-form solutions for both types of insurance in a single framework. It permits us to study the effect of risk sharing, insurance pricing, basis risk and preferences on the demand for both index and indemnity insurance.

Our second main contribution is to investigate the relationship between risk sharing and demand for index insurance - as well as indemnity insurance — in an artefactual field experiment. The participants are Ethiopian farmers who in their daily lives are exposed to aggregate weather shocks and share risk through informal arrangements. As far as we

\footnotetext{
${ }^{1}$ Index insurance is also referred to as parametric, or probabilistic, insurance (Kahneman and Tversky, 1979; Segal, 1988; Wakker et al., 1997; McIntosh et al., 2019). One prominent example of index insurance is Kilimo Salama, which covers 180,000 Kenyan farmers against drought and excess rainfall. Another is the Caribbean Catastrophe Risk Insurance Facility (CCRIF), set up by 16 Caribbean governments, which offers country-level index insurance against hurricanes and earthquakes. In both cases, insurance is offered to stakeholders who typically already share risk through pre-existing arrangements.
} 
know, this is the first study to control risk sharing exogenously and study its effect on demand for both types of insurance. Our approach avoids endogeneity concerns arising from the use of observational data, permitting identification of a causal relationship between risk sharing and insurance demand. The experimental results bear out the predictions of the theory: risk sharing increases the number of units of index insurance purchased, while it decreases the number of units of indemnity insurance purchased.

Varying the level of risk sharing experimentally in order to test its impact on insurance demand is clearly attractive from an identification perspective. ${ }^{2}$ It is also directly relevant to empirical settings where the level of risk sharing is relatively fixed because it is explicitly or implicitly contracted and deviation is associated with social sanctions. Such contractual rigidity has been widely documented in traditional risk-sharing arrangements (Besley et al., 1993; Dercon et al., 2006; Berg, 2018), suggesting that an exogenous level of risk sharing may be a reasonable assumption in a range of contexts, at least in the short term.

The participants in our artefactual field experiment are Ethiopian farmers who are members of $i d d i r$. Iddir are associations of individuals connected by ties of family, friendship, geographical area, occupation, or ethnic group (Mauri, 1967). The objective of an iddir is to provide mutual transfers and financial assistance in emergencies (Dercon et al., 2006; Pankhurst, 2008; Hoddinott et al., 2009; Aredo, 2010). The risk-sharing groups in our sample all have written rules for members, including regulations on the level of contributions and punishment for failure to comply. This context is especially suitable for the current study because iddir members are very familiar with informal risk-sharing transfers.

Our paper builds on a substantial literature on risk sharing and insurance. Early contributions showed that real-life risk-sharing arrangements generally fall short of providing full consumption smoothing (Cochrane, 1991; Mace, 1991; Townsend, 1994). Imperfect risk sharing may arise from limited commitment, information asymmetry and an inability to insure aggregate shocks (Coate and Ravallion, 1993; Attanasio and Pavoni, 2011). The role of formal insurance in this context is the subject of several papers including Arnott and Stiglitz (1991), Albarran and Attanasio (2003), Attanasio and Ríos-Rull (2000), Boucher and Delpierre (2014), De Janvry et al. (2014) and Janssens and Kramer (2016).

More specifically, this paper relates to recent work on the complementarity or substitutability of risk sharing and insurance. Our theoretical set-up is similar in spirit to Dercon et al. (2014), and we generate similar predictions, but in a considerably simpler

\footnotetext{
${ }^{2}$ The interaction between risk sharing and insurance is complex, as there are potential effects in both directions: the extent of risk sharing may influence the demand for formal insurance, but risk sharing may also be endogenous to the introduction of formal insurance. The experimental approach to studying such complex systems is to exogenously vary one part, and observe how the others respond. In this sense our approach is complementary to those of Anderberg and Morsink (2020) and Lenel and Steiner (2020), who vary the availability of insurance and study its effect on voluntary and non-reciprocal transfers.
} 
model. In the case of actuarially fair premia, our model is more general as we make no assumptions on the utility function beyond non-satiation and risk aversion, whereas Dercon et al. (2014) require additional assumptions on the third and fourth derivatives. Furthermore, we derive intuitive, closed-form solutions. In the case with marked-up premia and CRRA utility, we show that optimal insurance is linear in risk sharing and derive simple, analytical expressions for their slopes.

Mobarak and Rosenzweig (2012) model the demand for index insurance (but not indemnity insurance) in the presence of risk sharing. In a set-up with a pair of risksharing agents, they model aggregate and idiosyncratic risks as independent, additive shocks. They conclude that risk sharing may increase the demand for insurance when basis risk is high, but they do not sign the effect unambiguously. By contrast, we model risk as a single shock occurring with a probability that depends on the aggregate state (the index). This simplifies the analysis and allows basis risk to arise naturally within the framework rather than represent an additional assumption. The simplicity of the framework permits analytical solutions for demand (in the case of actuarially fair premia) or the slope of the demand curve (with marked-up premia).

We follow the most closely related literature in abstracting from asymmetric information issues, in particular moral hazard over the risk-taking behaviour of members of the risk-sharing group. We believe that the interaction of risk sharing and insurance under full information is interesting in its own right. ${ }^{3}$ It is also empirically relevant: many risksharing groups, especially in the context of small-scale agriculture, consist of members from close-knit rural communities where effort and risk taking are observable in practice. Several of the risk-sharing groups in our sample form committees that visit the plots of its members to advise on agricultural strategies. When effort is observable by members of a risk-sharing arrangement, moral hazard issues are likely to be of secondary concern to welfare (Arnott and Stiglitz, 1991).

We also contribute to the empirical literature on the complementarity or substitutability of risk sharing and insurance. It is known that indemnity insurance can crowd out risk sharing in both full and limited-commitment risk-sharing arrangements (Cutler and Gruber, 1996; Attanasio and Ríos-Rull, 2000; Albarran and Attanasio, 2003), but the relationship between index insurance and risk sharing has received less attention. Mobarak and Rosenzweig (2012) study the effect of risk sharing on demand for index insurance by offering insurance to Indian subcastes that vary in the degree to which they share risk. While the insurance offers are random, the level of risk sharing in these groups is not, so that the impact of risk sharing on index insurance is potentially confounded with other subcaste-level time-invariant factors. ${ }^{4}$

\footnotetext{
${ }^{3}$ In the context of the debate on whether the 'poor are rational', our results show that, in a controlled setting without moral hazard, insurance demand appears 'rational' and in accordance with expected utility theory.

${ }^{4}$ The authors also estimate the effect of risk sharing on index insurance demand indirectly, through
} 
Dercon et al. (2014) also empirically study the impact of risk sharing on demand for index insurance, by varying the framing of an insurance marketing intervention to Ethiopian farmers. In one treatment arm the marketing intervention emphasises how risk sharing can be used as a mechanism to manage basis risk. They find that this intervention, relative to an intervention that does not focus on risk sharing, increases demand for index insurance. However, it is not evident that the marketing intervention affects actual risk sharing, and it remains possible that the intervention influences demand for index insurance through other mechanisms.

McIntosh et al. (2019) investigate willingness to pay for index insurance when farmers have the option to share risk with peers in a cooperative. They find no significant impact of the risk-sharing option on demand for index insurance. They attribute this in large part to enforcement problems in the ex-post risk-sharing arrangement of the cooperative: because individuals are not expecting substantial risk sharing to actually occur, demand for index insurance does not increase. This is an important finding, but it leaves open the question of whether individuals would purchase more insurance if risk sharing was expected. In our model and experiment, we exogenously fix the extent of risk sharing to abstract from enforcement problems.

Three recent articles complement the present paper by studying the opposite direction of causality. Using artefactual field experiments, Anderberg and Morsink (2020) and Lenel and Steiner (2020) vary the availability of insurance in Ethiopian and Cambodian settings, respectively, and study its impact on voluntary, non-reciprocal transfers. In a natural field experiment, Takahashi et al. (2019) investigate the extent to which instrumented variation in demand for index insurance - varied in an encouragement design where discount coupons are distributed randomly - affects transfers among members of pre-existing informal risk-sharing groups of pastoralists in Ethiopia. They find that greater demand for index insurance does not compromise pre-existing informal social arrangements, and they provide suggestive evidence that it may even strengthen them.

There is also a growing body of research on the demand for index insurance more generally (Cole et al., 2013; Elabed et al., 2013; Clarke, 2016; Casaburi and Willis, 2018).

Our findings suggest that interventions that strengthen, build on, or encourage risk sharing of idiosyncratic losses can increase demand for index insurance and overall insurance coverage.

The rest of the paper is organised as follows. Section 2 presents our theoretical framework and key predictions. Section 3 describes the context and experimental design. Section 4 lays out the estimation strategy. Section 5 presents the results, and Section 6 concludes.

variation in the level of basis risk in the index insurance products offered. This is achieved by randomly placing weather stations in some villages rather than others. However, the extent of exogenous variation that this generates is small: out of 19 villages, they place a weather station in 12 and no weather station in 7 . 


\section{THEORY}

The key predictions of our theoretical framework are that index insurance is a complement to risk-sharing arrangements, whilst indemnity insurance acts as a substitute. We show this through three related models. The first two models assume insurance is actuarially fair, and serve simply to highlight the key intuition: the more agents engage in risk sharing, the more they need to be insured against common shocks, covered by index insurance, rather than individual-specific shocks, covered by indemnity insurance. The first, 'skeletal', model shows this in the simplest possible context, and the second model shows this in the context of standard insurance model with binary loss states. The third model, which we see as our primary theoretical contribution, generates the key predictions in the standard insurance model with binary loss states and marked-up premia.

\section{$2.1 \quad$ Skeletal model}

The central intuition can be illustrated using a 'skeletal' model as follows. An infinite number of risk-averse farmers maximise expected utility. Indexed by $i$, they have stochastic incomes $y_{i}$. Expected income, denoted $x$, is the same for all farmers and itself random, reflecting a common shock. An index is able to track $x$ perfectly and thus underpin an index insurance product against shocks to $x$.

The farmers implement a costless risk-sharing mechanism, whereby a proportion $\theta$ of each farmer's realised income is paid into a common kitty which is then evenly divided between them. Since the number of farmers is infinite, each receives an amount equal to the expected contribution, $E\left(\theta y_{i}\right)=\theta x$, from the kitty. So after risk sharing, farmer $i$ 's income is

$$
\theta x+(1-\theta) y_{i}
$$

Farmers also have access to indemnity and index insurance, which compensate for variation in $x$ and $y_{i}$, respectively.

Then if both insurance types are actuarially fairly priced, each risk-averse farmer will fully insure, as follows:

Result 1. In the skeletal model, each farmer purchases $\theta$ units of index insurance and $1-\theta$ units of indemnity insurance.

That is, the proportion of index insurance in the optimal insurance portfolio is equal to the proportion of the farmer's realised income that is paid into the risk-sharing pool. In other words, the greater the level of risk sharing in the community, the greater the demand for index insurance and the lower the demand for indemnity insurance.

Intuitively, indemnity insurance and risk sharing are substitutes because both serve 
the purpose of smoothing consumption within the group, that is, protecting against idiosyncratic shocks. And index insurance and risk sharing are complements because the greater the extent of risk sharing, the more the residual risk relates to the aggregate shock, which is covered by index insurance.

Note that this result does not require conditions on the utility function beyond the standard assumptions of non-satiation and risk aversion. Farmers need not have the same utility function. Furthermore, the result does not depend on the distributions of $x$ and $y_{i}$. In particular, it does not depend on whether farmers' incomes are correlated conditional on $x$.

\subsection{Binary loss and actuarially fair insurance}

The central intuition can be embedded in a more standard insurance framework with a binary loss state. This section studies the case of actuarially fair insurance and continues to assume only that the farmers are risk-averse. The next section studies the case with marked-up insurance premia for the CRRA family of utility functions.

As above, consider an infinite number of risk-averse farmers maximising expected utility. Each farmer has endowment $y$ and faces a possible loss $L<y$. With probability $q$, a shock occurs that is common to all farmers, henceforth referred to as a drought. If there is a drought, each farmer incurs the loss with probability $P$. If there is no drought, the loss is incurred with probability $p<P$. The expression $P-p$ can be interpreted as a measure of how predictive drought occurrence is of actual losses.

For simplicity we assume that farmer losses are independent conditional on drought outcome. ${ }^{5}$ In other words, all factors affecting the probability of loss, aside from the common shock, are assumed to be idiosyncratic and uncorrelated. However, unconditionally losses are positively correlated, since each farmer is more likely to incur the loss if there is a drought.

This loss and index structure is more in line with Clarke and Kalani (2011), Dercon et al. (2014), and Clarke (2016) than with Mobarak and Rosenzweig (2012) or Boucher and Delpierre (2014). Unlike the latter two papers, in our model there is either a loss or no loss for each participant, and the aggregate state does not affect wealth directly, but modifies the probability of loss.

However, unlike Mobarak and Rosenzweig (2012) and Dercon et al. (2014), but in common with Boucher and Delpierre (2014), we assume that the index tracks expected loss perfectly. This simplifying assumption allows us to focus on the trade-off between risk sharing and the demand for insurance. Continuing improvements in index insurance

\footnotetext{
${ }^{5}$ The direction of our predictions would not change if we allowed for conditionally correlated losses. It would mean that the level of risk sharing of idiosyncratic losses that can be achieved is lower and thus the demand for indemnity insurance will be higher.
} 
design also makes this assumption increasingly realistic. ${ }^{6}$

As in the skeletal framework above, the farmers engage in costless risk sharing: irrespective of individual outcomes, they all pay a proportion $\theta$ of their assets into a common kitty which is divided equally between them. Hence each farmer pays either $\theta y$ or $\theta(y-L)$, depending on individual outcome, into the kitty, and receives $\theta(y-P L)$ from the kitty if there is a drought and $\theta(y-p L)$ if there is not.

There are thus four possible outcomes for each farmer, as shown in Table 1.

Each farmer has access to two forms of insurance: indemnity insurance and index insurance. Let $\alpha$ be the number of units of indemnity insurance purchased by a farmer. Each unit of indemnity insurance pays out $L$ if and only if the farmer suffers an individual loss, irrespective of whether or not there is a drought. And let $\beta$ be the number of units of index insurance taken out. Each unit of index insurance pays out $L$ if and only if there is a drought, irrespective of whether the farmer suffers a loss.

Since both types of insurance are actuarially fair, premia equal expected losses. Hence the cost per unit of cover is $(q P+(1-q) p) L$ for indemnity insurance and $q L$ for index insurance.

With insurance, the outcome for a farmer in each state of the world is as shown in Table 2. (The probabilities are as in Table 1 and omitted to save space.) The second row in the table, where the index insurance pays out but there is no loss, represents the upside basis risk associated with index insurance. The third row in the table, where the farmer incurs a loss but the index insurance does not pay out, represents the downside basis risk associated with index insurance.

The farmers' problem is to maximise expected utility over these four outcomes with respect to insurance decisions $\alpha$ and $\beta$. At the optimum, the risk-averse farmers choose $\alpha$ and $\beta$ to ensure full consumption smoothing, such that in each of the four states of the world each farmer gets their autarchic expected income $y-(q P+(1-q) p) L$.

Simple algebraic rearrangement shows that this full consumption smoothing can be achieved by farmers purchasing indemnity and index insurance as follows.

Result 2. In the binary-loss insurance framework, optimal indemnity and index insurance purchases are given by:

$$
\begin{aligned}
& \alpha=1-\theta \quad \text { and } \\
& \beta=\theta(P-p)
\end{aligned}
$$

Since full consumption smoothing is achieved costlessly, this is an optimal solution for all

\footnotetext{
${ }^{6}$ Innovations in the design of index insurance products have led to indices that approximate expected income, such as average area yield or satellite indices based on Normalised Difference Vegetation Indices (NDVI).
} 
utility functions satisfying non-satiation and risk aversion.

The expressions for optimal insurance demand show how indemnity insurance and index insurance are, respectively, a substitute and a complement to risk sharing. Furthermore, the expression for $\beta$ reproduces a key result from Clarke (2016): demand for index insurance is decreasing in basis risk. This is because as $P-p$ decreases, the index is less informative of losses. Indeed, when $P=1$ and $p=0$, so that $P-p=1$, the index is perfectly informative of individual losses, and index insurance becomes equivalent to indemnity insurance. As the expressions for $\alpha$ and $\beta$ show, in this case one unit of effective indemnity insurance is bought.

Three key assumptions of this setup are worth noting. First, both types of insurance are assumed to be actuarially fair. In practice, while governments often subsidise insurance, privately provided insurance is generally sold with a mark-up. This assumption is relaxed in the next section where we consider the case of marked-up premia.

Second, our theoretical model assumes an infinite risk-sharing pool, which clearly does not obtain in practice. However, real risk-sharing groups are often comprised of relatively large networks of family and friends (Fafchamps and Lund, 2003), so an infinite risk-sharing pool may in some settings be more realistic than, or at least an alternative benchmark to, the two-person risk pools of, for example, Mobarak and Rosenzweig (2012) and Dercon et al. (2014). Furthermore, since these papers, along with that of Boucher and Delpierre (2014), generate similar results without the assumption of an infinite risksharing group, it is clear that the assumption of an infinite pool is not necessary to obtain similar theoretical results. Rather, the assumption serves to simplify the model and thereby highlight its intuition.

Third, we assume that the extent of risk sharing is fixed exogenously. This permits the isolation of the effect of risk sharing on insurance demand and is consistent with the experimental design. The assumption of exogenous risk sharing is also directly relevant to settings where participation in risk-sharing networks is socially enforced, and where local risk-sharing institutions are perhaps based on tradition and resistant to change.

\subsection{Binary loss and marked-up premia}

The sections above assumed that both types of insurance were sold with actuarially fair premia. This may be realistic in cases where insurance is subsidised. ${ }^{7}$ However, in practice insurance is often not fully subsidised. Furthermore, in theory the presence of fully subsidised indemnity insurance generates the question of why farmers wouldn't

\footnotetext{
${ }^{7}$ For example, the Weather Based Crop Insurance Scheme in India covers 9.3 million farmers. For farmers who grow food crops, the cost to the farmers themselves is less than $2 \%$ of the commercial premium. In Mexico, the cost of the index-based drought insurance provided by CADENA to 2 million smallholder farmers is fully assumed by the state and federal governments (Ritchie et al., 2016).
} 
simply purchase full indemnity insurance, rather than engage in a combination of risk sharing, index and indemnity insurance.

This section therefore examines the case of marked-up insurance premia. The model is otherwise exactly as above. However, only the constant relative risk aversion (CRRA) family of utility functions is considered.

Assume that indemnity insurance premia are marked up by a factor $M>1$ above the actuarially fair rate, and that index insurance premia are marked up by a factor $N>1$. It will be assumed that the mark-up on indemnity insurance is greater than that on index insurance, $M>N$. This assumption is based on the key conceptual advantages of index over indemnity insurance, including lower verification costs and reduced information asymmetry, and is also consistent with observed premia and with the literature. Clarke and Kalani (2011) use loadings of $60 \%$ for indemnity insurance and $20 \%$ for index insurance. Reported commercial loadings range from $70 \%$ to $430 \%$ for rainfall index insurance (Cole et al., 2013, Table 1) and from 140\% to 470\% for indemnity insurance (Hazell, 1992, Table 1).

The following additional quantities are defined for convenience:

$$
\begin{aligned}
r & =q P+(1-q) p \\
s & =M r \\
t & =N q \\
w & =t P+(1-t) p
\end{aligned}
$$

These are interpreted as follows: $r$ is the unconditional probability of loss occurrence, $s$ is the marked-up premium per unit of indemnity cover, $t$ is the marked-up premium per unit of index cover and $w$ is defined analogously to $r$, but where the probability of drought occurrence $q$ has been multiplied by $N$.

We will assume $s \leq 1$. This is plausible because a value of $s>1$ would imply that the cost of the indemnity insurance would exceed the insured loss, and no rational agent would buy it.

Consumption levels in the four states of the world are now as follows:

$$
\begin{aligned}
& c_{1}=y-L+\theta(1-P) L+\alpha(1-s) L+\beta(1-t) L \\
& c_{2}=y-\theta P L-\alpha s L+\beta(1-t) L \\
& c_{3}=y-L+\theta(1-p) L+\alpha(1-s) L-\beta t L \\
& c_{4}=y-\theta p L-\alpha s L-\beta t L
\end{aligned}
$$

The agent's problem is to set the insurance levels $\alpha$ and $\beta$ so as to maximise expected 
utility over these four states:

$$
\max _{\alpha, \beta} q P u\left(c_{1}\right)+q(1-P) u\left(c_{2}\right)+(1-q) p u\left(c_{3}\right)+(1-q)(1-p) u\left(c_{4}\right)
$$

Result 3. When the instantaneous utility function satisfies constant relative risk aversion, the optimal levels of insurance cover $\alpha$ and $\beta$ vary with the extent of risk sharing as follows:

$$
\begin{aligned}
& \frac{d \alpha}{d \theta}=-\frac{k+1-\alpha}{k+\theta} \\
& \frac{d \beta}{d \theta}=\frac{(P-p) k+\beta}{k+\theta}
\end{aligned}
$$

Here,

$$
k=\frac{y / L-s}{s-w}
$$

does not depend on $\theta, \alpha$ or $\beta$.

Proof. Introducing the short-hand notation $u_{i}^{\prime} \equiv u^{\prime}\left(c_{i}\right)$, the first-order conditions of the problem are given by:

$$
\begin{aligned}
& \frac{\partial E U}{\partial \alpha}=(1-s) q P u_{1}^{\prime}-s q(1-P) u_{2}^{\prime}+(1-s)(1-q) p u_{3}^{\prime}-s(1-q)(1-p) u_{4}^{\prime}=0 \\
& \frac{\partial E U}{\partial \beta}=(1-t) q P u_{1}^{\prime}+(1-t) q(1-P) u_{2}^{\prime}-t(1-q) p u_{3}^{\prime}-t(1-q)(1-p) u_{4}^{\prime}=0
\end{aligned}
$$

Consider an initial value for $\theta$. The optimal insurance levels $\alpha$ and $\beta$ for this level of risk sharing are implicitly given by the first-order conditions. Dividing these conditions by the mariginal utility in one of the four states of the world, say $u_{4}^{\prime}$, we obtain:

$$
\begin{aligned}
& (1-s) q P \frac{u_{1}^{\prime}}{u_{4}^{\prime}}-s q(1-P) \frac{u_{2}^{\prime}}{u_{4}^{\prime}}+(1-s)(1-q) p \frac{u_{3}^{\prime}}{u_{4}^{\prime}}-s(1-q)(1-p)=0 \\
& (1-t) q P \frac{u_{1}^{\prime}}{u_{4}^{\prime}}+(1-t) q(1-P) \frac{u_{2}^{\prime}}{u_{4}^{\prime}}-t(1-q) p \frac{u_{3}^{\prime}}{u_{4}^{\prime}}-t(1-q)(1-p)=0
\end{aligned}
$$

Since $s, t, q, P$ and $p$ are constants that do not depend on $\theta, \alpha$ or $\beta$, it is clear that, as $\theta$ is varied, the first-order conditions will remain satisfied as long as $u_{1}^{\prime}, \ldots, u_{4}^{\prime}$ stay in fixed proportion to each other.

For CRRA utility with parameter $\rho$, we have

$$
\frac{u_{i}^{\prime}}{u_{j}^{\prime}}=\left(\frac{c_{i}}{c_{j}}\right)^{-\rho},
$$

so this implies keeping the consumption levels $c_{1} \ldots c_{4}$ in fixed proportion to each other 
as $\theta$ is varied. Say,

$$
\frac{c_{1}}{c_{4}}=K_{1}, \quad \frac{c_{2}}{c_{4}}=K_{2} \quad \text { and } \quad \frac{c_{3}}{c_{4}}=K_{3},
$$

for constants $K_{1}, K_{2}$ and $K_{3}$.

Taking the natural logarithm and differentiating, we find:

$$
\frac{d \ln c_{1}}{d \theta}=\frac{d \ln c_{2}}{d \theta}=\frac{d \ln c_{3}}{d \theta}=\frac{d \ln c_{4}}{d \theta}
$$

Substituting in for the consumption levels and differentiating with respect to $\theta$ gives:

$$
\begin{array}{r}
\frac{1-P+(1-s) \frac{d \alpha}{d \theta}+(1-t) \frac{d \beta}{d \theta}}{y / L-1+(1-P) \theta+(1-s) \alpha+(1-t) \beta}=\frac{-P-s \frac{d \alpha}{d \theta}+(1-t) \frac{d \beta}{d \theta}}{y / L-P \theta-s \alpha+(1-t) \beta} \\
=\frac{1-p+(1-s) \frac{d \alpha}{d \theta}-t \frac{d \beta}{d \theta}}{y / L-1+(1-p) \theta+(1-s) \alpha-t \beta}=\frac{-p-s \frac{d \alpha}{d \theta}-t \frac{d \beta}{d \theta}}{y / L-p \theta-s \alpha-t \beta}
\end{array}
$$

This system contains only two linearly independent equations. Solving them for $\frac{d \alpha}{d \theta}$ and $\frac{d \beta}{d \theta}$ gives the expressions above.

Corollary 1. When indemnity insurance has a higher loading than index insurance, that is when $M>N$, demand for indemnity insurance decreases in risk sharing and demand for index insurance increases in risk sharing.

Proof. When $M>N$,

$$
\begin{aligned}
s-w & =M[q P+(1-q) p]-[N q P+(1-N q) p] \\
& =(M-N) r+(N-1) p \\
& >0 .
\end{aligned}
$$

Since $L<y$ and $s<1$, the ratio $k$ in Result 3 is positive. Then, as $\alpha \leq 1, \beta \geq 0, \theta \geq 0$ and $P>p$, it follows that $\frac{d \alpha}{d \theta}<0$ and $\frac{d \beta}{d \theta}>0$.

Corollary 2. The derivatives $\frac{d \alpha}{d \theta}$ and $\frac{d \beta}{d \theta}$ do not vary with $\theta$, that is, demand for indemnity insurance and demand for index insurance are both linear in risk sharing.

Proof. Differentiating the equations in Result 3 with respect to $\theta$ gives $\frac{d^{2} \alpha}{d \theta^{2}}=\frac{d^{2} \beta}{d \theta^{2}}=0$.

Corollary 3. The quantity

$$
\frac{1-\theta-\alpha}{(P-p) \theta-\beta}
$$

remains constant as $\theta$ varies. It can be interpreted as the ratio of the gap in indemnity insurance cover (relative to the no-loading, full insurance case) to the gap in index insurance cover.

Proof. From the proof of Result 3, we know that the ratios of the different consumption 
levels remain constant as $\theta$ varies. In particular,

$$
\frac{c_{2}}{c_{4}}=\frac{c_{4}+\beta L-(P-p) \theta L}{c_{4}}=1-\frac{(P-p) \theta L-\beta L}{c_{4}}
$$

and

$$
\frac{c_{3}}{c_{4}}=\frac{c_{4}-L+\alpha L+\theta L}{c_{4}}=1-\frac{L-\theta L-\alpha L}{c_{4}}
$$

are both constant. But then

$$
\frac{L-\theta L-\alpha L}{(P-p) \theta L-\beta L}=\frac{1-\theta-\alpha}{(P-p) \theta-\beta}
$$

is also constant.

Figure 1 illustrates optimal demand for insurance as a function of risk sharing when the utility function satisfies constant relative risk aversion (CRRA) with parameter $\rho \rightarrow 1$ (logarithmic utility), $\rho=2$ and $\rho=3$. The figure was generated by numerically optimising expected utility over $\alpha$ and $\beta$ with all other parameter values as in the experiment. ${ }^{8}$ It illustrates that the slopes of the demand curves, negative for indemnity insurance and positive for index insurance, do not depend on $\theta$ or $\rho$. It also shows that optimal $\alpha$ can be negative for sufficiently high $\theta$, implying that the agent would want to sell indemnity insurance.

\subsection{Summary of predictions}

All three theory sections generate the following two key predictions:

1. Demand for indemnity insurance decreases with the level of risk sharing.

2. Demand for index insurance increases with the level of risk sharing.

\section{CONTEXT AND EXPERIMENTAL DESIGN}

\subsection{Context}

The theoretical predictions were tested in an artefactual field experiment with 400 farmers from 10 villages in one district of Tigray, Ethiopia. These farmers were members of 14 different $i d d i r$. An iddir is an association of, typically, 50-200 individuals who are connected by ties of family, friendship, geographical area, occupation or ethnic group (Mauri, 1967). The objectives of an iddir are to provide mutual aid and financial assistance in case of emergencies. Iddir tend to have written statutes, by-laws and records of contributions and payouts. The rules define membership procedures, payout schedules, contributions

\footnotetext{
${ }^{8}$ That is, $y=200, L=100, q=1 / 6, P=5 / 6, p=1 / 6, M=1.44$ and $N=1.20$.
} 
and also a set of fines and other measures for non-payment of contributions (Aredo, 1993; Dercon et al., 2006; LeMay-Boucher, 2009). Iddir differ in the extent to which insurance contributions depend on the occurrence of a shock. One type only collects contributions when a shock occurs and payments are made directly to the member who incurs the loss. A second type collects a small monthly payment in addition to contributions when shocks occur. A third type collects only regular monthly payments from their members (insurance premia), saved in a communal iddir fund. Insurance claims by members are then paid out of this fund.

Iddir, especially those defined by a particular rural area, are stable institutions. In our sample, subjects report having been a member of their iddir for on average 10 years, with a maximum of 30 years. Eighty-four per cent of subjects report that they contribute only in case of shocks, $10 \%$ make monthly contributions, and $6 \%$ do both. In our sample, the average monthly contribution is 2 birr. $^{9}$ Average contributions in case of shocks are 13 birr, with a standard deviation of 22 birr. The iddir also institute committees that visit the agricultural land of their members, and advice on agricultural production strategies.

Because the experiment is concerned with the demand for both indemnity and index insurance, care was taken to select villages without prior exposure to either form of insurance. However, a number of index insurance products with a similar design to the product used in our experiment are offered to farmers in other parts of Ethiopia. Nyala Insurance and Oromia Insurance Company offer weather-based index insurance products to smallholder farmers. These products were taken up by 12,000 smallholder farmers in 2015 and 45,000 farmers in 2016. In 2016, Oromia paid out 2.6 million birr (USD 140,000) in claims. The contracts offer a fixed payout if cumulative monthly precipitation recorded at the nearest National Meteorological Agency station falls below a threshold that is calculated using data on past rainfall and yields. For 2017, 200,000-300,000 farmers have purchased index insurance products from these two companies. Payouts are made when a Normalised Difference Vegetation Index (NDVI), based on satellite data, falls below a defined threshold.

\subsection{Recruitment and selection}

The 400 farmers in our sample were randomly selected from ten randomly selected villages (kebele) in Hitalo Wajira district in Tigray, Ethiopia. Villages were selected subject to a maximum travel time from Mekele city of three hours and a minimum distance between the villages of ten kilometres. In advance of the study, permission was obtained from local administrative officials called Development Agents (DAs). The DAs provided lists of farmers for each village. The 40 farmers per village that participated in the study were randomly drawn from this list. The DA informed the farmers that they were invited to

\footnotetext{
${ }^{9}$ The exchange rate at the time of the experiment was 1 USD to 60 birr.
} 
participate in a survey and an experiment about weather, crops and agricultural decisionmaking. They were told that they could earn 100-200 birr and that the session would take no more than three hours. Farmers were also told that their answers to the survey and decisions in the experiment would be recorded by enumerators, but that responses would be anonymised. They were asked to come to the Farmer Training Centre in their village on the specified day. They would first take part in the experiment and then be fielded the survey. One hundred per cent of invited farmers attended. Subjects were informed that they would be given 200 birr in an envelope at the start of the session, and that during the experiment, they would be exposed to the risk of losing 100 birr. They were also told that they would be able to purchase insurance to mitigate the risk. The payoffs were substantial in the context of rural Ethiopia, where the daily wage for unskilled labour was in the range $50-150$ birr at the time.

\subsection{The experiment}

The experiments took place in the Farmer Training Centres. As soon as farmers entered, they were seated in private cubicles constructed from desks, chairs and cardboard dividers. The ten sessions were randomly allocated to four treatment arms, as shown in Table 3. Participants were provided with comprehensive training on the insurance game as a group and through individual instruction from the enumerators. The same eight enumerators were present at all the sessions, each enumerator in charge of training and collecting the responses for five subjects. Before the actual experiment, there were un-incentivised practice runs to aid and assess understanding. Since many of the subjects were illiterate, the experiment was explained orally with the help of visual aids, and physical randomisation devices (coloured tokens and dice). After playing the games, subjects were fielded a survey to collect background information.

\subsubsection{Aggregate and idiosyncratic shocks}

Subjects were introduced to the concepts of aggregate and idiosyncratic shocks. The aggregate shock in the game was framed as a possible region-wide drought, the occurrence of which depended on the colour of a token drawn from an envelope. There were 6 tokens in the envelope: 1 yellow and 5 blue. If the yellow token was drawn, the drought occurred, and if a blue token was drawn, it did not. The aggregate shock was drawn at the front of the room so that all participants could see.

Each participant then rolled a die to determine whether or not he or she would incur the loss. The type of die rolled by the individual participants depended on whether or not the drought occurred: If the drought occurred, each participant would roll a die with 5 yellow sides and 1 green side. If there was no drought, each participant would roll a die with 1 yellow side and 5 green sides. If a subject's die showed yellow, he or she suffered 
a loss of 100 birr, whereas a green die throw resulted in no loss.

Thus, as in the theory section, the aggregate shock (drought or not) was informative of the probability of suffering individual losses. Each participant's die throw was independent, and there was no group-level loss. But since the choice of die depended on the aggregate shock, farmer losses were unconditionally correlated. The probabilities and states of the game, before considering risk sharing and insurance, are presented in Figure 2. The unconditional expected net payoff in autarky was $200-2 \cdot(5 / 36) \cdot 100 \approx 172$ birr.

\subsection{Risk sharing}

As in our model, the extent of risk sharing was not left to the participants but varied experimentally. In the treatment arms without risk sharing, participants could not share risk with each other during the session. ${ }^{10}$

In the risk-sharing treatment arms, participants were randomly and anonymously paired with another participant in the same session. The identity of the partner was not revealed to participants. They were informed that, irrespective of the aggregate shock, insurance decisions and payouts, they would be sharing losses with their partner such that if one suffered the 100 birr loss but the other did not, then 50 birr would be transferred from the latter to the former. This corresponds to $\theta=1$ in the model.

In line with the model, losses were shared but insurance premia and payouts were not. Thus, in the absence of any insurance purchase and payouts, risk sharing participants' wealth would be the same, although differing decisions over insurance purchase could lead to different final outcomes. This setup ensures that participants do not have an incentive to free-ride on their partner's insurance, which might otherwise depress demand for insurance and confound the mechanism studied here (De Janvry et al., 2014; Janssens and Kramer, 2016). This is arguably realistic in an agricultural context where yield outcomes are observable to all, but insurance contracts are probably not.

\subsection{Insurance}

All subjects received information about indemnity and index insurance. They were told that indemnity insurance would pay out in the case of a loss, irrespective of whether or not the drought occurred, and that index insurance would pay out in the case of drought, irrespective of whether or not they incurred a loss.

Participants could purchase 0, 1 or 2 units of insurance. Each unit of insurance was associated with a payout of 50 birr, that is, half the potential loss. Hence, 2 units

\footnotetext{
${ }^{10}$ It is still possible that they shared risk after the session, even though subjects did not know with whom they were teamed up. But it is not clear that someone who had done well in the experiments would choose to reveal this. Even if they did, they might have difficulty identifying a deserving recipient, since it would be in everybody's interest to understate their earnings.
} 
would provide full insurance. The premium per unit of cover was 20 birr for indemnity insurance and 10 birr for index insurance. Table 4 presents unconditional probabilities, expected payouts and premia for the two insurance types. In line with the literature and commercial insurance pricing, indemnity insurance was priced with a higher loading (mark-up above the actuarially fair rate) than index insurance. ${ }^{11}$ Lower verification costs and reduced potential for moral hazard are two main reasons why index insurance can be expected to be sustainable at a lower mark-up than indemnity insurance. Given their different loadings, we do not attempt to compare the levels of demand for index and indemnity insurance to comment on which is more attractive, but rather we examine how demand for each varies when risk sharing is introduced.

Table 5 shows net payoffs for an individual participant for each state of the world and each possible insurance decision, in the absence of risk sharing. Net payoffs are given by the endowment (200), minus any insurance premia, minus the loss (100) if incurred, plus any insurance payout. From the table it is clear that participants in the index insurance treatments were exposed to downside basis risk with a probability of $5 / 36$.

The subjects' understanding of the game was assessed by conducting practice rounds where subjects were asked, based on their insurance decisions and the realisations of the aggregate shock and idiosyncratic losses, if they would receive a payout (yes or no) and how much the insurance claim payment would be (0, 50, 100 birr).

Table 6 summarises the structure and timing of the game.

\section{ESTIMATION STRATEGY}

We use three econometric specifications to estimate the effect of risk sharing on insurance demand. Because the outcome variable is discrete with three possible outcomes (each participant buys 0,1 or 2 units of insurance), we begin with an ordered probit. Next we run probit regressions where the outcome variable is a binary indicator for buying any (1 or 2 units) insurance versus none (0 units). Finally, we estimate a double probit hurdle model, where a first probit is used to model the decision regarding whether to buy insurance or not (the hurdle), and a second probit models the decision regarding whether to buy 1 or 2 units of insurance, conditional on buying at least one.

The key difference between the hurdle model and the ordered probit is that the hurdle model allows the outcome variable to be thought of as the result of two distinct choices by the participant, whereas in the ordered probit the decision is best thought of as a single choice. We use both models because it is uncertain how the decision processes of the subjects are best represented. However, all three specifications yield qualitatively similar results.

\footnotetext{
${ }^{11}$ Clarke and Kalani (2011) use loadings of $60 \%$ for indemnity insurance and $20 \%$ for index insurance. Reported commercial loadings range from $70 \%$ to $430 \%$ for rainfall index insurance (Cole et al., 2013, Table 1) and from $140 \%$ to $470 \%$ for indemnity insurance (Hazell, 1992, Table 1).
} 
It is helpful to define a latent variable $Y_{i}^{*}$ that is linear in the independent variables:

$$
Y_{i}^{*}=X_{i} \beta+\epsilon_{i}, \quad i=1, \ldots, N
$$

The vector of independent variables $X_{i}$ includes the main treatment variable (a binary indicator for risk sharing), a constant term and, depending on the specification, fixed effects and control variables. The error terms $\epsilon_{i}$ are standard normally distributed.

In the probit regressions, the binary dependent variable $Y_{i}$ is 0 if the subject buys 0 units of insurance and 1 if the subject buys 1 or 2 units of insurance. The observed binary outcome $Y_{i}$ is modelled as follows:

$$
Y_{i}=\left\{\begin{array}{ll}
0 & \text { if } Y_{i}^{*} \leq 0 \\
1 & \text { if } Y_{i}^{*}>0
\end{array}, \quad i=1, \ldots, N\right.
$$

For the ordered probit regressions, the latent variable $Y_{i}^{*}$ is defined as above. But now the observed outcome variable (the number of units of insurance purchased) $Y_{i}$ takes on values 0 through 2 according to the scheme

$$
Y_{i}= \begin{cases}0 & \text { if } Y_{i}^{*} \leq \mu_{1} \\ 1 & \text { if } \mu_{1}<Y_{i}^{*} \leq \mu_{2} \\ 2 & \text { if } Y_{i}^{*}>\mu_{2}\end{cases}
$$

where $\mu_{1}$ and $\mu_{2}$ are threshold parameters to be estimated along with the coefficients $\beta$. The probability of each outcome is:

$$
\begin{aligned}
& \operatorname{Pr}\left(Y_{i}=0\right)=\Phi\left(\mu_{1}-X_{i} \beta\right) \\
& \operatorname{Pr}\left(Y_{i}=1\right)=\Phi\left(\mu_{2}-X_{i} \beta\right)-\Phi\left(\mu_{1}-X_{i} \beta\right) \\
& \operatorname{Pr}\left(Y_{i}=2\right)=1-\Phi\left(\mu_{2}-X_{i} \beta\right)
\end{aligned}
$$

Here, $\Phi$ is the cumulative distribution function for the standard normal. The likelihood for the ordered probit can be written

$$
L=\prod_{i=1}^{N} \sum_{n=0}^{2} \mathbb{1}\left\{Y_{i}=n\right\} \operatorname{Pr}\left(Y_{i}=n\right),
$$

where $\mathbb{1}\{\}$ is the indicator function.

To allow for the possibility that the data have been generated through a process whereby subjects separately decide to purchase zero or a positive amount of insurance, and then decide the number of units to purchase (Mullahy, 1986; Cameron and Trivedi, 1998; Botelho et al., 2009), we estimate the parameters of a double probit hurdle model 
(Cribari-Neto and Zeileis, 2009). The first probit, with outcome $Y_{i}^{\prime}$, determines whether the individual buys at least 1 unit of insurance. This is the 'hurdle'. The second probit, with outcome $Y_{i}^{\prime \prime}$, determines whether the individual buys 1 or 2 units of insurance, conditional on buying at least 1 .

Thus, in the hurdle model, the number of units of insurance purchased is given by

$$
Y_{i}=Y_{i}^{\prime}\left(1+Y_{i}^{\prime \prime}\right)
$$

Denoting by $\beta^{\prime}$ and $\beta^{\prime \prime}$ the parameter vectors for the first and second probit, respectively, the likelihood function for the hurdle model is

$$
\begin{aligned}
L= & \prod_{i \in \Omega_{0}} \Phi\left(-\beta^{\prime} X_{i}\right) \cdot \prod_{i \in \Omega_{1} \cup \Omega_{2}} \Phi\left(\beta^{\prime} X_{i}\right) \\
& \cdot \prod_{i \in \Omega_{1}} \Phi\left(-\beta^{\prime \prime} X_{i}\right) \cdot \prod_{i \in \Omega_{2}} \Phi\left(\beta^{\prime \prime} X_{i}\right),
\end{aligned}
$$

where $\Omega_{0}=\left\{i \mid Y_{i}=0\right\}$ is the set of non-purchasers and $\Omega_{1}=\left\{i \mid Y_{i}=1\right\}, \Omega_{2}=\left\{i \mid Y_{i}=2\right\}$ are the subjects who choose 1 and 2 units of insurance, respectively.

\section{RESULTS}

Of the 400 subjects who started the session, three were unable to complete due to unanticipated family or work engagements. These three were excused and received their participation fee. Each of the four questions testing understanding in the practice rounds were answered correctly by more than $80 \%$ of subjects. $72 \%$ of the subjects answered all four questions correctly.

Table 7 presents summary statistics for each of the four treatment arms: indemnity insurance without (column 1) and with (column 2) risk sharing, and index insurance without (column 4) and with (column 5) risk sharing. As these arms technically form two separate experiments, one for each type of insurance, we test for balance separately. Column 3 presents $t$-tests for equality of means across the indemnity insurance treatments, and column 6 does the same for index insurance. Out of 20 balance tests, equality is rejected at the $5 \%$ level for only one (marital status for index insurance). This rejection rate is close to what would be expected statistically (5\%), but we still present regressions that control for all these observable characteristics.

As well as repeating the means, Table 8 shows the proportion of individuals purchasing 0,1 or 2 units of insurance by treatment. The proportion of individuals purchasing at least one unit of indemnity insurance decreases from 0.99 to 0.86 when risk sharing is introduced, while the proportion of individuals purchasing at least one unit of index insurance increases (doubles) from 0.46 to 0.93 .

Regression analysis confirms these findings. Table 9 shows ordered probit regression 
results for the number of units of insurance purchased (0,1 or 2). Columns 2, 3, 5, and 6 include enumerator fixed effects. Column 3 and 6 also control for sex, age, age squared, marital status, household headship, literacy, household size, livestock owned in Tropical Livestock Units and land owned in hectares. In all regressions, the risk-sharing coefficient is significant at the $1 \%$ level. For indemnity insurance, the overall effect is negative, as predicted by the theory. The effect is driven by an increase in the probability that subjects purchase 0 or 1 unit of insurance, and a decrease in the probability that subjects purchase 2 units of insurance. For index insurance, the overall effect is positive, implying that risk sharing increases demand for index insurance, as predicted. The effect is driven by a reduction in the probability that individuals purchase 0 units of insurance and an increase in the probability that subjects purchase 2 units of insurance.

Table 10 presents probit regressions where the dependent variable is an indicator for whether the participant bought a positive amount (1 or 2 units) of insurance. In line with the predictions, risk sharing decreases the probability of buying indemnity insurance (by approximately 20\%), while it increases the probability of buying index insurance (by approximately 35\%). The risk-sharing coefficient is everywhere significant at the $1 \%$ level.

Table 11 shows maximum-likelihood estimates for the hurdle model. In column 1, it is shown that the probability of buying any indemnity insurance, and also the probability of buying two units of insurance conditional on buying at least one, both decrease significantly with risk sharing. This is robust to the inclusion of enumerator fixed effects and control variables in columns 2 and 3. Furthermore, and with reference to the lower half of the table, risk sharing increases the predicted probability of buying 0 or 1 unit of indemnity insurance, but decreases the probability of buying 2 units. For indemnity insurance, the coefficients on risk sharing are everywhere significant at the $1 \%$ level.

For index insurance (columns 4-6), risk sharing is associated with a positive and significant (at the 1\% level) increase in the propensity to buy at least one unit of insurance. The effect on the propensity to buy two units of insurance, conditional on buying at least one, is also positive but not significant at the $5 \%$ level. Risk sharing decreases the predicted probability of buying no insurance, and increases the predicted probabilities of buying both 1 and 2 units.

Thus the hurdle model confirms the ordered probit results, but suggests that, for index insurance, the main effect of risk sharing is to increase the probability of buying some insurance rather than to increase the number of units purchased from 1 to 2 . For indemnity insurance, it appears that risk sharing decreases both the propensity to buy some insurance rather than no insurance, and also the propensity to buy 2 units conditional on buying at least 1.

Table 12 presents a robustness check where the ten sessions are left out of the regressions one by one. All specifications are ordered probit regressions and include enumerator 
fixed effects and control variables. In the upper panel, it is shown that the negative and significant effect of risk sharing on the demand for indemnity insurance is robust to dropping any of the six indemnity-insurance sessions from the analysis. The risk-sharing coefficient is everywhere significant at the $1 \%$ level. In the lower panel, it is shown that the positive and significant effect of risk sharing on the demand for index insurance is robust to dropping three out of four sessions (significant at the 1\% level). When dropping session 8 , one of the index insurance sessions without risk sharing, the coefficient on risk sharing remains positive but is no longer statistically significant.

Given that there were only six indemnity insurance and four index insurance sessions, and the consequent loss of power associated with dropping one of them, we believe that the robustness check confirms that our main results are not driven by any one outlying session.

\section{CONCLUSION}

We present a parsimonious theoretical framework and show that risk sharing is a substitute for indemnity insurance but a complement to index insurance. To test these predictions we present the first experimental evidence on demand for indemnity and index insurance where the extent of risk sharing is varied exogenously. In an artefactual field experiment with low-income farmers in Ethiopia, who share risk in real life, the theoretical predictions are confirmed. This highlights the importance of considering existing risk-sharing arrangements when introducing formal insurance contracts and, in particular, the potential for traditional arrangements to boost demand for index insurance.

\section{References}

Albarran P, Attanasio O (2003) Limited commitment and crowding out of private transfers: Evidence from a randomised experiment. Economic Journal 113(486):C77-C85

Anderberg D, Morsink K (2020) The introduction of formal insurance and its effect on redistribution. Journal of Economic Behavior and Organization 179:22-45

Aredo D (1993) The iddir: A study of an indigenous informal financial institution in Ethiopia. Savings and Development 17(1):77-90

Aredo D (2010) The Iddir: An informal insurance arrangement in Ethiopia. Savings and Development 34(1):53-72

Arnott R, Stiglitz JE (1991) Moral hazard and nonmarket institutions: Dysfunctional crowding out or peer monitoring? American Economic Review 81(1):179-190

Attanasio O, Pavoni N (2011) Risk sharing in private information models with asset accumulation: Explaining the excess smoothness of consumption. Econometrica 79(4):10271068 
Attanasio O, Ríos-Rull JV (2000) Consumption smoothing in island economies: Can public insurance reduce welfare? European Economic Review 44(7):1225-1258

Attanasio O, Ríos-Rull JV (2000) Consumption Smoothing in Island Economies: Can Public Insurance Reduce Welfare? European Economic Review 44(7):1225-1258

Berg E (2018) Funeral insurance: An inter-generational commitment device? Journal of African Economies 27(3):321-346

Besley T, Coate S, Loury G (1993) The economics of rotating savings and credit associations. American Economic Review 83(4):792-810

Botelho A, Harrison GW, Pinto LMC, Rutström EE (2009) Testing static game theory with dynamic experiments: A case study of public goods. Games and Economic Behavior 67(1):253-265

Boucher S, Delpierre M (2014) The impact of index-based insurance on informal risksharing arrangement, Luxembourg Institute of Socio-Economic Research (LISER) Working Paper 13

Cameron C, Trivedi PK (1998) Regression analysis of count data. Cambridge University Press

Casaburi L, Willis J (2018) Time versus state in insurance: Experimental evidence from contract farming in Kenya. American Economic Review 108(12):3778-3813

Clarke DJ (2016) A theory of rational demand for index insurance. American Economic Journal: Microeconomics 8(1):283-306

Clarke DJ, Dercon S (2016) Dull disasters? How planning ahead will make a difference. Oxford University Press

Clarke DJ, Kalani G (2011) Microinsurance decisions: Evidence from Ethiopia. In: Insurance Design for Developing Countries, DPhil thesis, Daniel Clarke, University of Oxford

Coate S, Ravallion M (1993) Reciprocity without commitment: Characterization and performance of informal insurance arrangements. Journal of Development Economics 40(1):1-24

Cochrane JH (1991) A simple test of consumption insurance. Journal of Political Economy 99(5):957-976

Cole S, Giné X, Tobacman J, Topalova P, Townsend R, Vickery J (2013) Barriers to household risk management: Evidence from india. American Economic Journal: Applied Economics 5(1):104-135

Cribari-Neto F, Zeileis A (2009) Beta regression in R, https://cran.rproject.org/web/packages/betareg/vignettes/betareg.pdf

Cutler DM, Gruber J (1996) The effect of Medicaid expansions on public insurance, private insurance, and redistribution. American Economic Review 86(2):378-383 
De Janvry A, Dequiedt V, Sadoulet E (2014) The demand for insurance against common shocks. Journal of Development Economics 106:227-238

Dercon S, De Weerdt J, Bold T, Pankhurst A (2006) Group-based funeral insurance in Ethiopia and Tanzania. World Development 34(4):685-703

Dercon S, Hill RV, Clarke D, Outes-Leon I, Taffesse AS (2014) Offering rainfall insurance to informal insurance groups: Evidence from a field experiment in Ethiopia. Journal of Development Economics 106:132-143

Elabed G, Bellemare MF, Carter MR, Guirkinger C (2013) Managing basis risk with multiscale index insurance. Agricultural Economics 44(4-5):419-431

Fafchamps M, Lund S (2003) Risk-sharing networks in rural Philippines. Journal of Development Economics 71(2):261-287

Hazell PBR (1992) The appropriate role of agricultural insurance in developing countries. Journal of International Development 4(6):567-581

Hoddinott J, Dercon S, P (2009) Networks and Informal Mutual Support in 15 Ethiopian Villages. Institutional Economics Perspectives on African Agricultural Development

Janssens W, Kramer B (2016) The social dilemma of microinsurance: Free-riding in a framed field experiment. Journal of Economic Behavior \& Organization 131(B):47-61

Kahneman D, Tversky A (1979) Prospect theory: An analysis of decision under risk. Econometrica 47(2):263-292

LeMay-Boucher P (2009) Beninese and Ethiopian informal insurance groups: A comparative analysis. Development Policy Review 27(3):333-347

Lenel F, Steiner S (2020) Formal insurance and solidarity. Experimental evidence from Cambodia. Journal of Economic Behavior and Organization 174:212-234

Mace B (1991) Consumption volatility: Borrowing constraints or full insurance. Journal of Political Economy 99(5):928-956

Mauri A (1967) Il mercato del credito in Etiopia. A. Giuffrè, 20

McIntosh C, Povel F, Sadoulet E (2019) Utility, risk, and demand for incomplete insurance: Lab experiments with Guatemalan co-operatives. The Economic Journal 129(622):2581-2607

Mobarak AM, Rosenzweig MR (2012) Selling formal insurance to the informally insured, Yale Economics Department Working Paper 97

Mullahy J (1986) Specification and testing of some modified count data models. Journal of Econometrics 33(3):341-365

Pankhurst A (2008) The emergence, evolution and transformations of iddir funeral associations in urban Ethiopia. Journal of Ethiopian Studies 41(1/2):143-185 
Ritchie ER, de Janvry A, Sadoulet E (2016) Weather index insurance and shock coping: Evidence from Mexico's CADENA program. World Bank Policy Research Working Paper 7715

Samphantharak K, Townsend RM (2018) Risk and return in village economies. American Economic Journal: Microeconomics 10(1):1-40

Segal U (1988) Probabilistic insurance and anticipated utility. Journal of Risk and Insurance 55(2):287-297

Takahashi K, Barrett CB, Ikegami M (2019) Does index insurance crowd in or crowd out informal risk sharing? Evidence from rural Ethiopia. American Journal of Agricultural Economics 101(3):672-691

Townsend RM (1994) Risk and insurance in village india. Econometrica 62(3):539-591

Wakker P, Thaler R, Tversky A (1997) Probabilistic insurance. Journal of Risk and Uncertainty 15(1):7-28 


\section{A. EXPERIMENTAL INSTRUCTIONS}

[Instructions for enumerators and session leaders in italic font.]

[Instructions for participants in regular font.]

There are four types of sessions: Indemnity insurance without risk sharing, indemnity insurance with risk sharing, index insurance without risk sharing, and index insurance with risk sharing. Each participant takes part in only one session, and all forty participants in a session are members of the same iddir. Since most subjects are illiterate, each decision problem is explained with visual aids. All sessions start with a group-level introduction, followed by a number of un-incentivised practice games and then the main, incentivised, experiment. Throughout it is important to explain to the participants that the main experiment will affect their earnings, while the practice games do not. At the end of the session, a survey is fielded to each participant.

First a simple "drought and loss" practice game is played, without risk sharing or insurance. The aim is to familiarise participants with the basic risk structure of the experiment. Then, the insurance concepts are introduced. This is followed by practice games for indemnity insurance, index insurance, and risk sharing. Finally, the main experiment is conducted. Care is taken to explain that the final experiment involves real monetary payoffs.

\section{A.1 Introduction}

Tables are numbered 1-40 and the assigned number of the participant is preceded by the session number, for example, for session 4 and participant 11: 4.11. In all sessions the session leader reads the following to the participants:

Thank you for participating. In this experiment we will ask you to make decisions about insurance against possible monetary losses that will be determined by drawing tokens and rolling dice. You will receive an initial endowment of 200 birr at the start of the experiment. In the event that you experience a loss, the loss amount will be taken from your initial endowment.

You will have the option of buying insurance. It is up to you to decide whether to buy insurance or not. There is no right or wrong answer. We are interested in learning about what you prefer.

The session will take no more than three hours. At the start you will be given 200 birr, and you may experience a loss of 100 birr. You will be offered different insurance products against the payment of an insurance premium. The insurance premium will be deducted from your endowment. Your net pay will depend on your decisions as well as the token drawn and the die rolled. This means that you should think carefully about the decisions you make.

On the table in front of you there is a white envelope containing 200 birr and two dice, one blue and one yellow. Please count the money and check that the dice are there. You will now receive instructions but later on, when we play the experiment, you may lose some of the money.

We kindly request that you do not discuss with the other participants, and that you make your decisions in private. One of the enumerators will come 
to you to record your decisions. If you have a question about the experiment, you can ask your enumerator.

Before we play the main experiment, we will explain everything carefully and play some practice rounds. These practice rounds will not involve real money.

\section{A.2 The drought and loss game}

In all sessions the session leader reads the following to the participants:

I have six tokens in front of me; five are blue and one is yellow. Let's imagine that the blue tokens represent good weather - no drought - and the yellow token represents drought. I will put these tokens in a bag and draw one. If I draw the yellow token this means that there is a drought. If I draw a blue token this means that there is no drought. The outcome of this draw is common to all participants in the room.

The session leader now plays two rounds.

Even though the draw of the weather outcome through the tokens is the same for all of you, the quality of your yield may differ. In drought years, some farmers may still have a good crop, and in no-drought years, some farmers may still have a bad crop. However, in no-drought years you are more likely to have a good crop, while in drought years you are more likely to have a bad crop.

In front of you are two dice, one yellow and one blue, corresponding to the colour of the tokens. The yellow die has one green side (good crop) and five yellow sides (bad crop). If a yellow token (drought) is drawn, all participants will throw the yellow die. In drought years it is more likely that your crop will be bad (five out of six) but there is still a chance that your crop is good (one out of six).

The blue die has five green sides (good crop) and one yellow side (bad crop). If a blue token (no drought) is drawn, everybody will throw this die. In nodrought years, it is more likely that your crop will be good (five out of six), but there is still a chance that your crop is bad (one out of six).

Now you are all asked to throw the die that corresponds to the token drawn. This will determine if you experience a loss (bad crop, yellow side) or not (good crop, green side).

The participants play two practice rounds. In these practice rounds, the session leader draws a blue token once and a yellow token once, and the participants throw the corresponding die. The enumerators check that the correct die is used, and explain what the net payout to the participant would be based on the endowment and die throw.

\section{A.3 Introducing indemnity insurance}

In all sessions, the session leader reads the following to the participants: 
I will now introduce you to indemnity insurance. It pays out if you incur a loss, irrespective of whether there is a drought. That is, payout is tied to your individual die throw rather than the group token. The overall probability of incurring a loss in the drought game is 5/18. You will incur a loss of 100 birr if the die throw results in a yellow side. You will not incur a loss if your die throw results in a green side.

The overall probability of throwing yellow is 5/18. A fair premium that covers your whole loss is then 28 birr $\left(5 / 18^{*} 100\right)$. There is a $44 \%$ loading that represents the costs for the administration of the insurance.

You will have the option of buying indemnity insurance against the loss. You can buy 0,1 , or 2 units of insurance. Each unit of insurance costs 20 birr and pays out 50 birr in case of a loss. So buying 2 units of insurance costs 40 birr and pays out 100 birr in case of a loss.

Two practice rounds of the game with insurance are played. The enumerator records the outcomes and choices of the participants.

Practice round 1: no drought

1. Does the participant want to take out insurance? Record 0, 1 or 2 units, and let the participants pay the correct premium.

2. A blue session-level token is selected, implying that there is no drought.

3. Each participant throws a die to determine their individual outcome. The enumerator verifies that the correct die (the one with five green sides and one yellow side) is used and records the outcome, yellow or green. Let the participant pay 100 birr in case of loss (yellow die throw).

4. Ask the participant: Do you think you will get an insurance payout? Record yes or no.

5. Ask the participant: How much do you think you will get in insurance payout? Record 0 birr, 50 birr or 100 birr.

6. Pay out the correct amount (50 or 100 birr) if participant has insurance and the die outcome is yellow.

7. Remind the participant that this was a practice round and reverse payments.

Practice round 2: drought. Repeat the steps above, but select the yellow token and ensure participants throw the die with five yellow sides and one green side.

\section{A.4 Introducing index insurance}

In all sessions, the session leader reads the following to the participants:

A second type of insurance is index insurance. It pays out if there is a drought, irrespective of whether you incur a loss. That is, the payout is tied to the group token draw rather than your individual die throw. The probability of a drought occurring in the drought game is $1 / 6$. An actuarially fair premium is therefore 17 birr. With $20 \%$ loading this implies a premium of 20 birr. Index 
insurance can be cheaper than indemnity insurance, but there is a risk that you will not receive a payout (because there is no drought) even though you incur the loss.

You will incur a loss of 100 birr if your die throw results in a yellow side. You will not incur a loss if your die throw results in a green side. The insurance pays out if and only if there is a drought, irrespective of whether you incur a loss. So it is the token from the bag, and not the die throw (crop loss), that determines payout. It is therefore possible (if the token is blue but your die throw is yellow) to experience the 100 birr loss and still not receive a payout.

You can buy 0 , 1, or 2 units of insurance. Each unit of insurance costs 10 birr and pays out 50 birr in the case of a drought. So buying 2 units of insurance costs 20 birr and pays out 100 birr in the case of a drought.

Two practice rounds of the game with index insurance are played. The enumerator records the outcomes and choices of the participants.

Practice round 1: no drought

1. Does the participant want to take out insurance? Record 0, 1 or 2 units, and let the participants pay the correct premium.

2. A blue session-level token is selected, implying that there is no drought.

3. Each participant throws a die to determine their individual outcome. The enumerator verifies that the correct die (the one with five green sides and one yellow side) is used and records the outcome, yellow or green. Let the participant pay 100 birr in case of loss (yellow die throw).

4. Ask the participant: Do you think you will get an insurance payout? Record yes or no.

5. Ask the participant: How much do you think you will get in insurance payout? Record 0 birr, 50 birr or 100 birr.

6. There is no insurance payout because the token draw is blue.

7. Remind the participant that this was a practice round and reverse payments.

Practice round 2: drought. Repeat the steps above, but select the yellow token and ensure participants throw the die with five yellow sides and one green side. Now all participants with insurance will receive a payout as the token is yellow.

\section{A.5 Introducing risk sharing}

In all sessions, the session leader reads the following to the participants:

In the next practice game you will still be able to buy insurance, but instead of bearing losses on your own, you will now share losses with another participant in this session. You will not learn who this other person is, nor will they learn who you are. Losses will be shared irrespective of the insurance decisions made by you and the other person. So, if one of you suffers the 100 birr loss and the other doesn't, 50 birr will be transferred to the person with the loss 
from the person without the loss. If neither of you incurs a loss, or if both do, then no transfer is made.

Two practice rounds of the game with risk sharing are played, one for indemnity insurance and one for index insurance. The enumerator records the outcomes and choices of the participants.

Practice round 1: Indemnity insurance with risk sharing

1. Does the participant want to take out insurance? Record 0, 1 or 2 units, and let the participants pay the correct premium.

2. A session-level token is drawn to determine whether or not a drought occurs. The outcome of this draw is common to all participants in a session and determines the die to be thrown by the individual participants. Record the colour of the token drawn, blue or yellow.

3. Each participant throws a die to determine their individual outcome. The enumerator verifies that the correct die is used (depending on the token drawn) and records the outcome, yellow or green. Let the participant pay 100 birr in case of loss (yellow die throw).

4. Ask the participant to wait while the enumerator verifies from the session leader whether or not the risk-sharing partner incurred a loss. Explain the partner's outcome to the participant and make the correct risk-sharing adjustment: pay 50 birr, receive 50 birr or no transfer.

5. Ask the participant: Do you think you will get an insurance payout? Record yes or no.

6. Ask the participant: How much do you think you will get in insurance payout? Record 0 birr, 50 birr or 100 birr.

7. Give the insurance payout to the participant if the outcome of the die throw is yellow.

8. Remind the participant that this was a practice round and reverse payments.

Practice round 2: index insurance with risk sharing. Repeat the steps above, but charge the correct premium for index insurance and condition the insurance payout on the draw of the token, not on the die roll.

\section{A.6 The main (incentivised) experiment and survey}

The session leader reads to the participants:

So far we have been playing practice games in order to increase your understanding. The final game, played with real money, will now start. Whatever is left of the 200 birr after the token draw, die roll and transfers is yours to keep and does not have to be returned to the session leader or enumerator. After the experiment is finished, the enumerator will come to you and ask some questions about you and your household, farm and iddir. Please wait until the enumerator instructs you that everything is finished and that you may leave. We are very grateful for your participation. 
Depending on the session, participants are told that the final game will involve indemnity or index insurance, and that it will be played with or without risk sharing. The enumerator records the outcomes and choices of the participants.

1. Does the participant want to take out insurance? Record 0, 1 or 2 units, and let the participants pay the correct premium.

2. A session-level token is drawn to determine whether or not a drought occurs. The outcome of this draw is common to all participants in a session and determines the die to be thrown by the individual participants. Record the colour of the token drawn, blue or yellow.

3. Each participant throws a die to determine their individual outcome. The enumerator verifies that the correct die is used (depending on the token drawn) and records the outcome, yellow or green. Let the participant pay 100 birr in case of loss (yellow die throw).

4. In sessions with risk sharing only: Ask the participant to wait while the enumerator verifies from the session leader whether or not the risk-sharing partner incurred a loss. Explain the partner's outcome to the participant and make the correct risksharing adjustment: pay 50 birr, receive 50 birr or no transfer.

5. Give the correct insurance payout to participant. In indemnity-insurance sessions, the payout is made if the outcome of the die throw is yellow. In index-insurance sessions, the payout is made if the token drawn is yellow. Either way, if a payout is made, the participant receives 50 birr for each unit of insurance purchased. 
Table 1: Outcomes after risk sharing, without insurance

\begin{tabular}{llll}
\hline Drought & Loss & Probability & Outcome after risk sharing \\
\hline Yes & Yes & $q P$ & $\theta(y-P L)+(1-\theta)(y-L)$ \\
Yes & No & $q(1-P)$ & $\theta(y-P L)+(1-\theta) y$ \\
No & Yes & $(1-q) p$ & $\theta(y-p L)+(1-\theta)(y-L)$ \\
No & No & $(1-q)(1-p)$ & $\theta(y-p L)+(1-\theta) y$ \\
\hline
\end{tabular}

Table 2: Outcomes after risk sharing and insurance

\begin{tabular}{lll}
\hline Drought & Loss & Outcome after risk sharing and insurance \\
\hline Yes & Yes & $\theta(y-P L)+(1-\theta)(y-L)-\alpha(q P+(1-q) p) L-\beta q L+\alpha L+\beta L$ \\
Yes & No & $\theta(y-P L)+(1-\theta) y-\alpha(q P+(1-q) p) L-\beta q L+\beta L$ \\
No & Yes & $\theta(y-p L)+(1-\theta)(y-L)-\alpha(q P+(1-q) p) L-\beta q L+\alpha L$ \\
No & No & $\theta(y-p L)+(1-\theta) y-\alpha(q P+(1-q) p) L-\beta q L$ \\
\hline
\end{tabular}

Table 3: Number of sessions by treatment arm

\begin{tabular}{lcc}
\hline & Indemnity insurance & Index insurance \\
\hline Without risk sharing & 3 & 2 \\
With risk sharing & 3 & 2 \\
\hline
\end{tabular}

Note: Allocation of sessions to the four treatment arms. In all, ten sessions were held, and each participant in a session received the same treatment. 
Table 4: Characteristics of insurance products offered

\begin{tabular}{lcc}
\hline & Indemnity insurance & Index insurance \\
\hline Payout per unit of cover & 50 & 50 \\
Unconditional probability of payout & $5 / 18$ & $1 / 6$ \\
Expected payout (=actuarially fair premium) & $125 / 9 \approx 13.9$ & $25 / 3 \approx 8.3$ \\
Premium charged per unit of cover & 20 & 10 \\
Implied loading / mark-up above fair premium & $44 \%$ & $20 \%$ \\
\hline
\end{tabular}

Note: Each participant was offered either indemnity or index insurance, but not both, and could choose between 0,1 or 2 units of cover. The premia were set so as to make the loadings roughly in line with the literature. 
Table 5: States and payoffs

\begin{tabular}{|c|c|c|c|c|c|c|}
\hline \multirow[b]{2}{*}{ Prob } & \multirow[b]{2}{*}{ State } & \multirow[b]{2}{*}{ Units } & \multicolumn{2}{|c|}{ Payoff with indemnity insurance } & \multicolumn{2}{|c|}{ Payoff with index insurance } \\
\hline & & & Calculation & Net & Calculation & Net \\
\hline \multirow[t]{3}{*}{$5 / 36$} & \multirow{3}{*}{$\begin{array}{l}\text { Drought, } \\
\text { loss }\end{array}$} & 0 & $200-100$ & 100 & $200-100$ & 100 \\
\hline & & 1 & $200-20-100+50$ & 130 & $200-10-100+50$ & 140 \\
\hline & & 2 & $200-2 \cdot 20-100+2 \cdot 50$ & 160 & $200-2 \cdot 10-100+2 \cdot 50$ & 180 \\
\hline \multirow[t]{3}{*}{$1 / 36$} & \multirow{3}{*}{$\begin{array}{l}\text { Drought, } \\
\text { no loss }\end{array}$} & 0 & 200 & 200 & 200 & 200 \\
\hline & & 1 & $200-20$ & 180 & $200-10+50$ & 240 \\
\hline & & 2 & $200-2 \cdot 20$ & 160 & $200-2 \cdot 10+2 \cdot 50$ & 280 \\
\hline \multirow[t]{3}{*}{$5 / 36$} & \multirow{3}{*}{$\begin{array}{l}\text { No drought, } \\
\text { loss }\end{array}$} & 0 & $200-100$ & 100 & $200-100$ & 100 \\
\hline & & 1 & $200-20-100+50$ & 130 & $200-10-100$ & 90 \\
\hline & & 2 & $200-2 \cdot 20-100+2 \cdot 50$ & 160 & $200-2 \cdot 10-100$ & 80 \\
\hline \multirow[t]{3}{*}{$25 / 36$} & \multirow{3}{*}{$\begin{array}{l}\text { No drought, } \\
\text { no loss }\end{array}$} & 0 & 200 & 200 & 200 & 200 \\
\hline & & 1 & $200-20$ & 180 & $200-10$ & 190 \\
\hline & & 2 & $200-2 \cdot 20$ & 160 & $200-2 \cdot 10$ & 180 \\
\hline
\end{tabular}

Note: Payoffs in birr for each combination of drought, loss, type of insurance and number units of insurance purchased. The (no drought, loss) state is where index insurance leads to downside basis risk. Risk-sharing transfers (for participants in risk-sharing sessions only) come in addition. 
Table 6: Insurance game timing

1. Each participant is given a 200 birr endowment.

2. Each participant buys insurance (0,1 or 2 units) and pays the premium.

3. The aggregate shock is drawn at the group (session) level.

4. Each participant rolls a die to determine whether (s)he incurs a loss.

5. Participants incurring a loss pay 100 birr to enumerator.

6. Participants are informed of their partner's loss outcome.

7. Any loss is shared with partner: receive 50, send 50 or no adjustment.

8. Insurance pays out.

Note: The italicised steps only apply to treatment arms with risk sharing. 
Table 7: Summary statistics and balance checks

\begin{tabular}{|c|c|c|c|c|c|c|}
\hline & $\begin{array}{c}(1) \\
\text { Indemnity } \\
\text { insurance, } \\
\text { without } \\
\text { risk } \\
\text { sharing }\end{array}$ & $\begin{array}{c}(2) \\
\text { Indemnity } \\
\text { insurance, } \\
\text { with } \\
\text { risk } \\
\text { sharing }\end{array}$ & $\begin{array}{c}(3) \\
\text { Difference } \\
t \text {-test } \\
(2)-(1)\end{array}$ & $\begin{array}{c}(4) \\
\text { Index } \\
\text { insurance, } \\
\text { without } \\
\text { risk } \\
\text { sharing }\end{array}$ & $\begin{array}{c}(5) \\
\text { Index } \\
\text { insurance, } \\
\text { with } \\
\text { risk } \\
\text { sharing }\end{array}$ & $\begin{array}{c}(6) \\
\text { Difference } \\
t \text {-test } \\
(5)-(4)\end{array}$ \\
\hline Female & $\begin{array}{c}0.37 \\
(0.48)\end{array}$ & $\begin{array}{c}0.39 \\
(0.49)\end{array}$ & $\begin{array}{c}0.025 \\
(0.063)\end{array}$ & $\begin{array}{c}0.47 \\
(0.50)\end{array}$ & $\begin{array}{c}0.42 \\
(0.50)\end{array}$ & $\begin{array}{l}-0.045 \\
(0.080)\end{array}$ \\
\hline Age & $\begin{array}{c}48.0 \\
(13.6)\end{array}$ & $\begin{array}{c}44.7 \\
(13.5)\end{array}$ & $\begin{array}{l}-3.28^{*} \\
(1.75)\end{array}$ & $\begin{array}{c}42.3 \\
(13.9)\end{array}$ & $\begin{array}{c}38.6 \\
(10.1)\end{array}$ & $\begin{array}{l}-3.68^{*} \\
(1.96)\end{array}$ \\
\hline Married & $\begin{array}{c}0.84 \\
(0.37)\end{array}$ & $\begin{array}{c}0.82 \\
(0.39)\end{array}$ & $\begin{array}{l}-0.016 \\
(0.050)\end{array}$ & $\begin{array}{c}0.80 \\
(0.40)\end{array}$ & $\begin{array}{c}0.62 \\
(0.49)\end{array}$ & $\begin{array}{c}-0.18^{* *} \\
(0.074)\end{array}$ \\
\hline Household head & $\begin{array}{c}0.88 \\
(0.32)\end{array}$ & $\begin{array}{c}0.88 \\
(0.32)\end{array}$ & $\begin{array}{c}0.00100 \\
(0.042)\end{array}$ & $\begin{array}{c}0.91 \\
(0.28)\end{array}$ & $\begin{array}{c}0.97 \\
(0.16)\end{array}$ & $\begin{array}{l}0.062^{*} \\
(0.037)\end{array}$ \\
\hline Literate & $\begin{array}{c}0.55 \\
(0.50)\end{array}$ & $\begin{array}{c}0.59 \\
(0.49)\end{array}$ & $\begin{array}{c}0.037 \\
(0.065)\end{array}$ & $\begin{array}{c}0.40 \\
(0.49)\end{array}$ & $\begin{array}{c}0.50 \\
(0.50)\end{array}$ & $\begin{array}{c}0.10 \\
(0.080)\end{array}$ \\
\hline Household size & $\begin{array}{c}5.41 \\
(1.82)\end{array}$ & $\begin{array}{c}5.57 \\
(1.71)\end{array}$ & $\begin{array}{c}0.16 \\
(0.25)\end{array}$ & $\begin{array}{c}5.35 \\
(2.22)\end{array}$ & $\begin{array}{c}4.97 \\
(1.90)\end{array}$ & $\begin{array}{l}-0.39 \\
(0.37)\end{array}$ \\
\hline $\begin{array}{l}\text { Tropical } \\
\text { livestock units }\end{array}$ & $\begin{array}{l}1.86 \\
(2.42)\end{array}$ & $\begin{array}{c}1.80 \\
(1.81)\end{array}$ & $\begin{array}{r}-0.061 \\
(0.28)\end{array}$ & $\begin{array}{l}1.46 \\
(1.60)\end{array}$ & $\begin{array}{c}1.86 \\
(1.66)\end{array}$ & $\begin{array}{c}0.40 \\
(0.26)\end{array}$ \\
\hline $\begin{array}{l}\text { Land owned, } \\
\text { in hectares }\end{array}$ & $\begin{array}{c}0.72 \\
(0.39)\end{array}$ & $\begin{array}{c}0.66 \\
(0.38)\end{array}$ & $\begin{array}{l}-0.063 \\
(0.050)\end{array}$ & $\begin{array}{c}0.64 \\
(0.31)\end{array}$ & $\begin{array}{c}0.64 \\
(0.39)\end{array}$ & $\begin{array}{l}0.0047 \\
(0.056)\end{array}$ \\
\hline Observations & 120 & 120 & . & 80 & 80 & . \\
\hline
\end{tabular}

Note: Summary statistics and balance checks. Columns 1, 2, 4 and 5 present means of variables by treatment arm, with standard deviations in parentheses. Columns 3 and 6 present difference $t$-tests, with standard errors in parentheses. ${ }^{*} p<0.10,{ }^{* *} p<0.05,{ }^{* * *} p<0.01$ 
Table 8: Insurance demand by treatment

\begin{tabular}{ccccc}
\hline & $\begin{array}{c}\text { Indemnity } \\
\text { insurance } \\
\text { without } \\
\text { risk sharing }\end{array}$ & $\begin{array}{c}\text { Indemnity } \\
\text { insurance } \\
\text { with } \\
\text { risk sharing }\end{array}$ & $\begin{array}{c}\text { Index } \\
\text { insurance } \\
\text { without } \\
\text { risk sharing }\end{array}$ & $\begin{array}{c}\text { Index } \\
\text { insurance } \\
\text { with } \\
\text { risk sharing }\end{array}$ \\
\hline Proportion who purchase. & & & & \\
no insurance (0 units) & 0.01 & 0.14 & 0.54 & 0.08 \\
partial insurance (1 unit) & 0.26 & 0.46 & 0.32 & 0.48 \\
full insurance (2 units) & 0.73 & 0.40 & 0.14 & 0.45 \\
some insurance (1 or 2 units) & 0.99 & 0.86 & 0.46 & 0.93 \\
Mean units purchased & 1.73 & 1.26 & 0.60 & 1.38 \\
\hline
\end{tabular}

Table 9: Ordered probit regressions of units of insurance purchased

\begin{tabular}{|c|c|c|c|c|c|c|}
\hline & \multicolumn{3}{|c|}{$\begin{array}{l}\text { Units of indemnity } \\
\text { insurance purchased }\end{array}$} & \multicolumn{3}{|c|}{$\begin{array}{c}\text { Units of index } \\
\text { insurance purchased }\end{array}$} \\
\hline & $(1)$ & $(2)$ & $(3)$ & $(4)$ & $(5)$ & $(6)$ \\
\hline Risk sharing & $\begin{array}{c}-0.93^{* * *} \\
(0.16)\end{array}$ & $\begin{array}{c}-0.92^{* * *} \\
(0.16)\end{array}$ & $\begin{array}{c}-1.10^{* * *} \\
(0.18)\end{array}$ & $\begin{array}{c}1.23^{* * *} \\
(0.19)\end{array}$ & $\begin{array}{c}1.28^{* * *} \\
(0.19)\end{array}$ & $\begin{array}{c}1.03^{* * *} \\
(0.23)\end{array}$ \\
\hline \multicolumn{7}{|c|}{ Marginal change in probability of buying. . } \\
\hline zero units & 0.12 & 0.11 & 0.13 & -0.36 & -0.35 & -0.24 \\
\hline one unit & 0.21 & 0.21 & 0.23 & 0.0084 & 0.010 & 0.0065 \\
\hline two units & -0.33 & -0.32 & -0.36 & 0.35 & 0.34 & 0.24 \\
\hline Enumerator fixed effects & No & Yes & Yes & No & Yes & Yes \\
\hline Controls & No & No & Yes & No & No & Yes \\
\hline
\end{tabular}

Note: Ordered probit regressions. The dependent variable is the number of units of insurance purchased. Columns 3 and 6 include control variables for sex, age, age squared, marital status, household headship, literacy, household size, livestock owned in Tropical Livestock Units and land owned in hectares. Robust standard errors are in parentheses. ${ }^{*} p<0.10, * * p<0.05, * * * p<0.01$ 
Table 10: Probit regressions

\begin{tabular}{|c|c|c|c|c|c|c|}
\hline & \multicolumn{3}{|c|}{$\begin{array}{l}\text { Indemnity insurance } \\
\text { purchased }\end{array}$} & \multicolumn{3}{|c|}{$\begin{array}{l}\text { Index insurance } \\
\text { purchased }\end{array}$} \\
\hline & (1) & $(2)$ & $(3)$ & $(4)$ & $(5)$ & $(6)$ \\
\hline Risk sharing & $\begin{array}{c}-1.32^{* * *} \\
(0.39)\end{array}$ & $\begin{array}{c}-1.35^{* * *} \\
(0.39)\end{array}$ & $\begin{array}{c}-1.77^{* * * *} \\
(0.51)\end{array}$ & $\begin{array}{c}1.53^{* * *} \\
(0.25)\end{array}$ & $\begin{array}{c}1.62^{* * *} \\
(0.25)\end{array}$ & $\begin{array}{c}1.81^{* * *} \\
(0.38)\end{array}$ \\
\hline \multicolumn{7}{|c|}{ Marginal change in probability of buying any insurance } \\
\hline & -0.16 & -0.17 & -0.23 & 0.41 & 0.42 & 0.32 \\
\hline Enumerator fixed effects & No & Yes & Yes & No & Yes & Yes \\
\hline Controls & No & No & Yes & No & No & Yes \\
\hline
\end{tabular}


Table 11: Double probit hurdle model

\begin{tabular}{|c|c|c|c|c|c|c|}
\hline & \multicolumn{3}{|c|}{$\begin{array}{c}\text { Units of indemnity } \\
\text { insurance purchased }\end{array}$} & \multicolumn{3}{|c|}{$\begin{array}{c}\text { Units of index } \\
\text { insurance purchased }\end{array}$} \\
\hline & (1) & $(2)$ & (3) & $(4)$ & $(5)$ & (6) \\
\hline $\begin{array}{r}\operatorname{Pr}(Y \in\{1,2\}): \\
\text { Risk sharing }\end{array}$ & $\begin{array}{c}-1.32^{* * * *} \\
(0.39)\end{array}$ & $\begin{array}{c}-1.35^{* * *} \\
(0.39)\end{array}$ & $\begin{array}{c}-1.77^{* * *} \\
(0.51)\end{array}$ & $\begin{array}{c}1.53^{* * *} \\
(0.25)\end{array}$ & $\begin{array}{c}1.62^{* * *} \\
(0.25)\end{array}$ & $\begin{array}{c}1.81^{* * *} \\
(0.38)\end{array}$ \\
\hline $\begin{array}{l}\operatorname{Pr}(Y=2 \mid Y \in\{1,2\}) \text { : } \\
\text { Risk sharing }\end{array}$ & $\begin{array}{c}-0.73^{* * *} \\
(0.18)\end{array}$ & $\begin{array}{c}-0.74^{* * *} \\
(0.18)\end{array}$ & $\begin{array}{c}-0.92^{* * *} \\
(0.21)\end{array}$ & $\begin{array}{l}0.50^{*} \\
(0.26)\end{array}$ & $\begin{array}{l}0.49^{*} \\
(0.28)\end{array}$ & $\begin{array}{c}0.16 \\
(0.36)\end{array}$ \\
\hline $\begin{array}{l}\text { Marginal change in proba } \\
\text { zero units } \\
\text { one unit } \\
\text { two units }\end{array}$ & $\begin{array}{c}\text { bility of b } \\
0.13 \\
0.20 \\
-0.33\end{array}$ & $\begin{array}{r}\text { xying. . } \\
0.13 \\
0.20 \\
-0.33\end{array}$ & $\begin{array}{c}0.16 \\
0.21 \\
-0.37\end{array}$ & $\begin{array}{c}-0.46 \\
0.15 \\
0.31\end{array}$ & $\begin{array}{c}-0.46 \\
0.18 \\
0.28\end{array}$ & $\begin{array}{c}-0.43 \\
0.24 \\
0.18\end{array}$ \\
\hline $\begin{array}{l}\text { Enumerator fixed effects } \\
\text { Controls }\end{array}$ & $\begin{array}{l}\text { No } \\
\text { No }\end{array}$ & $\begin{array}{l}\text { Yes } \\
\text { No }\end{array}$ & $\begin{array}{l}\text { Yes } \\
\text { Yes }\end{array}$ & $\begin{array}{l}\text { No } \\
\text { No }\end{array}$ & $\begin{array}{l}\text { Yes } \\
\text { No }\end{array}$ & $\begin{array}{l}\text { Yes } \\
\text { Yes }\end{array}$ \\
\hline
\end{tabular}

Note: Double probit hurdle model estimates. The dependent variable is the number of units of insurance purchased. Columns 3 and 6 include control variables for sex, age, age squared, marital status, household headship, literacy, household size, livestock owned in Tropical Livestock Units and land owned in hectares. Robust standard errors are in parentheses. ${ }^{*} p<0.10,{ }^{* *} p<0.05,{ }^{* * *} p<0.01$ 
Table 12: Robustness check: Leaving out sessions one by one

\begin{tabular}{|c|c|c|c|c|c|c|c|}
\hline & \multicolumn{7}{|c|}{ Units of indemnity insurance purchased } \\
\hline & $(1)$ & $(2)$ & $(3)$ & $(4)$ & $(5)$ & $(6)$ & $(7)$ \\
\hline Risk sharing & $\begin{array}{c}-1.10^{* * * *} \\
(0.18)\end{array}$ & $\begin{array}{c}-0.74^{* * *} \\
(0.20)\end{array}$ & $\begin{array}{c}-0.84^{* * *} \\
(0.21)\end{array}$ & $\begin{array}{c}-1.34^{* * *} \\
(0.22)\end{array}$ & $\begin{array}{c}-1.30 * * * \\
(0.23)\end{array}$ & $\begin{array}{c}-1.23^{* * *} \\
(0.20)\end{array}$ & $\begin{array}{c}-1.62^{* * *} \\
(0.25)\end{array}$ \\
\hline $\begin{array}{l}\text { Enumerator } \\
\text { fixed effects }\end{array}$ & Yes & Yes & Yes & Yes & Yes & Yes & Yes \\
\hline Controls & Yes & Yes & Yes & Yes & Yes & Yes & Yes \\
\hline \multirow[t]{3}{*}{ Session dropped } & None & $\# 1$ & $\# 2$ & $\# 5$ & $\# 6$ & $\# 9$ & $\# 10$ \\
\hline & \multicolumn{7}{|c|}{ Units of index insurance purchased } \\
\hline & (1) & $(2)$ & (3) & $(4)$ & $(5)$ & & \\
\hline Risk sharing & $\begin{array}{c}1.03^{* * *} \\
(0.23)\end{array}$ & $\begin{array}{c}10.8^{* * *} \\
(1.38)\end{array}$ & $\begin{array}{c}1.31^{* * *} \\
(0.27)\end{array}$ & $\begin{array}{c}0.84^{* * *} \\
(0.31)\end{array}$ & $\begin{array}{c}0.24 \\
(0.28)\end{array}$ & & \\
\hline $\begin{array}{l}\text { Enumerator } \\
\text { fixed effects }\end{array}$ & Yes & Yes & Yes & Yes & Yes & & \\
\hline Controls & Yes & Yes & Yes & Yes & Yes & & \\
\hline Session dropped & None & $\# 3$ & $\# 4$ & $\# 7$ & $\# 8$ & & \\
\hline
\end{tabular}

Note: Ordered probit regressions, leaving out one session at a time. The dependent variable is the number of units of insurance purchased. All regressions include enumerator fixed effects and control variables for sex, age, age squared, marital status, household headship, literacy, household size, livestock owned in Tropical Livestock Units and land owned in hectares. Robust standard errors are in parentheses. $* p<0.10$, ** $p<0.05$, *** $p<0.01$ 
Figure 1: Optimal insurance demand as a function of risk sharing



Risk sharing $(\theta)$

Note: Numerically estimated optimal demand for indemnity $(\alpha)$ and index $(\beta)$ insurance as a function of the risk-sharing parameter $(\theta)$. All parameters are as in the experiment, and the utility function satisfies constant relative risk aversion (CRRA) with parameter values $\rho \rightarrow 1$ (logarithmic utility), $\rho=2$ and $\rho=3$. The slopes of the demand curves, negative for $\alpha$ and positive for $\beta$, do not depend on $\theta$ or $\rho$. Note that optimal $\alpha$ can be negative, implying that agents would want to sell, rather than buy, indemnity insurance when $\theta$ is sufficiently high. 
Figure 2: Aggregate shock and idiosyncratic losses

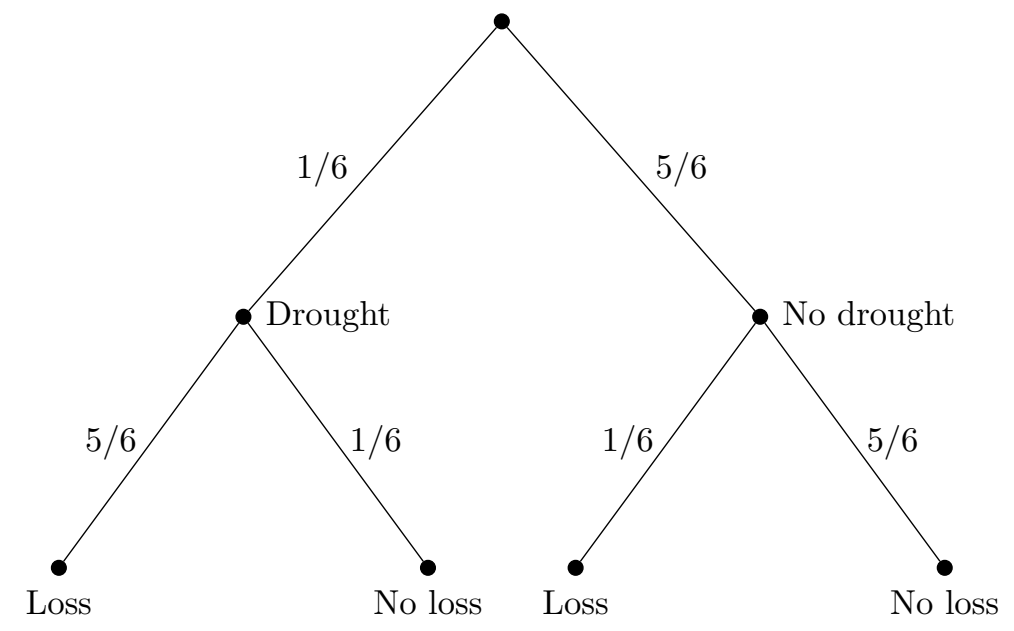

Note: Extensive-form autarchy game. Probabilities are presented next to the branches of the tree. The states are presented at the nodes of the tree representing drought, no drought, loss and no loss. The drought occurs with probability $1 / 6$. The loss occurs with probability $5 / 6$ if there is a drought and with probability $1 / 6$ if not. 